\title{
Integrating and Distinguishing Personality and Psychopathology
}

\author{
Aidan G.C. Wright \\ University of Pittsburgh \\ Christopher J. Hopwood \\ University of Zurich
}

This manuscript has been accepted and is in press at the Journal of Personality. It is not the final copy of record.

Aidan Wright's effort was supported by the National Institute of Alcohol Abuse and Alcoholism (R01 AA026879).

The authors have no conflicts of interest to report.

Correspondence concerning this article should be addressed to Aidan G.C. Wright, Department of Psychology, University of Pittsburgh, 4119 Sennott Square, 210 S. Bouquet St., Pittsburgh, PA, 15260.E-mail: aidan@pitt.edu 


\begin{abstract}
We asked authors of this Special Issue to answer four questions: 1) Is there evidence that personality and psychopathology can be integrated?, 2) Is integration important?, 3) Can they be distinguished?, and 4) How can the difference be measured?. Authors uniformly agreed that personality and psychopathology can be integrated within a common structure and that this is important. The third and fourth questions were more challenging. While authors generally agreed that there is a distinction between the person and the person's mental health problems, articulations of that distinction were fuzzy and it is clear that current methods are not sufficiently capable of delineating these domains. We summarize the issue by offering four directions for future research: 1) develop measurement tools that distinguish between the person, the context, and their transaction, 2) measure behavior and context at multiple timescales, 3) use multimethod data to tap different levels of behavior, and 4) examine person-specific processes. Each of these directions comes with considerable challenges, but the payoff of solving them will be a more principled, evidence-based, and clinically-useful model for the distinction between personality and psychopathology.
\end{abstract}

Keywords: personality, psychopathology, traits, symptoms, dysfunction 


\section{Integrating and Distinguishing Personality and Psychopathology}

How are people and their problems related, and how are they distinct? In classical theories of individual differences from psychiatry and clinical psychology, personality and psychopathology were deeply intertwined, often conceptualized as manifesting within the same, integrated system. Clinical theorists referred to personality when they described their patient's difficulties (Rogers, 1951; Sullivan, 1953), and a comprehensive assessment to diagnose psychopathology was thought to require a personality assessment (Harris, 1950; Rappaport, Gill, Schafer, 1946). However, various historical factors split apart personality and psychopathology in the highly influential Diagnostic and Statistical Manual for Mental Disorders (DSM), and thereby in mainstream psychological science and clinical psychology/psychiatry. Given that the motivating force behind the split was insufficient empirical evidence for those early theories, it is ironic that the accumulated data has returned the field to the view that individual differences in personality and psychopathology may ultimately occupy the same empirical space. This is reflected in emerging systems like the Hierarchical Taxonomy of Psychopathology (HiTOP; Kotov et al., 2017, 2021), which has five principal spectra of dysfunction with unmistakable parallels to the five domains of the five-factor model of basic personality traits (DeYoung et al., this issue; Widiger et al., 2019).

From our vantage point as clinically trained personality psychologists, we see the present as a critical time in the history of personality and psychopathology. The empirical data seem to strongly support a push towards rapprochement and integration, but due in part to the Faustian bargains of the DSM, other lingering missteps of the past, and inherent natural complexities, there are enduring challenges to developing comprehensive models of personality and psychopathology. Currently, the degree to which personality is incorporated in theorizing and 
active research programs varies widely across psychopathologists, such that there are those who largely ignore personality in conceptualizing psychopathology, those who think of personality only in terms of the personality disorders, those who take for granted that the two are distinct, and those who advocate making personality everything, drawing little if any distinction between the two. None of these approaches seem to adequately address the question of how personality and psychopathology are related and might be adequately distinguished. Therefore, there is a pressing need for scientific work that clarifies empirically the relationship between the two in the service of comprehensive models of human (dys)function, which in turn has important public health implications.

Within the fields of personality and psychopathology, theoretical diversity abounds. Therefore, we sought a plurality of perspectives on the nature of the personalitypsychopathology relationship, including psychometric, genetic, developmental, neurobiological, psychodynamic, cognitive-behavioral, game theory, computational, and idiographic points of view for this Special Issue. Most authors contributed theoretical pieces, though some brought new data and analyses to the table for consideration. Each was asked to engage with four straightforward, but as it turns out very difficult, questions:

1) Is there evidence that personality and psychopathology can be integrated?

2) Is integration important?

3) Can they be distinguished?

4) How can the difference be measured?

Before considering the answers to each of these questions, we first place them within a historical context, which is useful for explaining why the time is ripe for considering how personality and psychopathology might be merged and distinguished and why it might be beneficial to each 
field.

\section{Personality and Psychopathology in an Historical Context}

The historical trajectory of personality psychology and clinical psychology/psychiatry are both relevant for this discussion, though the clinical sciences have arguably had the larger influence on how the relationship between personality and psychopathology is understood. The first and second editions of the DSM were published by the American Psychiatric Association $(1952,1968)$ at a time when psychoanalytic thinking was the predominant theoretical model of both personality and psychopathology in American psychiatry. The diagnoses listed in these early versions of the manual were largely impressionistic psychoanalytic descriptions of character disorders (e.g., passive aggressive personality disorder) and symptom reactions (e.g., manic depressive reaction). Psychoanalytic theory understood personality and psychopathology as elements of a holistic, integrated system. However, evidence-based methods for reliably distinguishing these elements from one another were lacking.

DSM-III (American Psychiatric Association, 1980) was a milestone in the history of psychiatric diagnosis notable for its turn toward a descriptivist, medical model approach, in which the goal was to reliably describe observable syndromes that differed from one another in ways thought to be important for etiology, prognosis, and treatment (Robins \& Guze, 1970). At a fundamental level, psychoanalytic inferences about the deep and typically hidden sources of human variation are incompatible with the goal of describing observable (i.e., not hidden) behaviors. Therefore, the psychoanalytic community, which remains an influential contingent within psychiatry, forced the first of two Faustian bargains, and it would have an enduring effect on how clinical researchers would come to view personality. Despite the fact that they were fundamentally incompatible with the DSM-III's approach to diagnosis, psychoanalytic constructs 
were retained in the manual, albeit on a separate axis of diagnosis, Axis II. Instead of being regarded as the personality context of symptom disorders, they were conceptualized as a handful of discrete personality disorders. The stated goal of this arrangement was that clinicians would be encouraged to formulate the symptom disorders of their patients within the underlying context of the character structure of each patient (Williams, 1985). This largely didn't happen. Instead, financial, theoretical, and historical factors converged such that the personality disorders were often ignored by clinicians. Psychopathology became separated from personality in the work of many clinical researchers and practitioners. In the context of clinical diagnosis, personality began to signify a subgroup of patients who were thought of as difficult to engage with and unlikely to improve (i.e., those with frank personality disorders), rather than "what people are like". In retrospect, one unintended consequence of the DSM-III era's emphasis on reliability and validity was the separation of personality from psychopathology, and a move away from whole-person models of clinical problems.

Meanwhile, trait psychology had emerged within personality science as a major complement to psychoanalytic theory (Goldberg, 1990; Wiggins, 1996). It adopted a descriptive, quantitative empirical approach from the outset (i.e., factor analysis; see Wright, 2017). Though not exclusively, much of the field's focus was on establishing a universal structure of personality through the use of factor analytic techniques applied to various trait descriptive terms or phrases. As the diagnoses on the DSM-III's pages were becoming psychiatric cannon through the 1980's and early 1990's, trait psychology was converging on the most prominent of the 'big-few' personality trait models, the big-five or five-factor model (Digman, 1990; Mottus et al., 2020). Armed with a consensus model, personality-minded clinical psychologists now could marshal the literature linking personality and psychopathology, organizing new systematic research, all 
around a common standard (e.g., Kotov et al., 2010; Samuel \& Widiger, 2008; Saulsman \& Page, 2004).

This approach, especially as applied to personality disorders, ultimately has had a marked impact on psychiatry. By the time DSM-5 was set to be developed, dimensional models were at the forefront of discussions about how and what in the manual should be revised (Krueger et al., 2007). Ultimately, a dimensional trait model of personality pathology was included in DSM-5. However, it is becoming clear that this development represented a second Faustian bargain. This is because, like was the case in DSM-III, the broader communities of psychiatry and clinical psychology have disparate intellectual factions that are not always easily integrated. Thus, the DSM-5 Alternative Model of Personality Disorders marries a psychoanalytic model for distinguishing personality pathology from adaptive personality functioning (i.e., Criterion A), with a maladaptive variant of "big-five" trait model for distinguishing individual differences in personality pathology (i.e., Criterion B) (Mulay et al., 2018). In an effort to placate the parties to the bargain, the model resulted in several inefficiencies, redundancies, and inconsistencies. For instance, it has been noted that Criterion A and B have overlapping, and sometimes indistinguishable content (e.g., lack of empathy in Criterion A, callousness in Criterion B). Or, it was suggested that clinicians assess for specific personality disorder categories first, and then assess dimensional traits if needed, even though the latter is a prerequisite to the former. Moreover, due to various political maneuverings, it was included as a provisional or alternative model in need of more study, so it didn't wholly replace the existing categories (Zachar et al., 2016). In contrast, the recently released International Classification of Disease, Eleventh Edition (World Health Organization, 2019) did introduce a simplified model of personality disorder based more heavily on trait psychology, in which most remnants of developmental 
psychoanalytic theory have been abandoned or reconfigured.

The past two decades have also seen the emergence of dimensional systems for reorganizing or reclassifying psychopathology writ large (Dalgleish et al., 2020). The HiTOP system has clear parallels to the structural literature in basic personality, in that it has its provenance in personality-minded clinical psychologists adopting the same tools (i.e., latent variable modeling) for the study of the quantitative empirical structure of psychopathology (e.g., Krueger, 1999; Krueger et al., 1998). This approach accelerated in the years leading up to DSM5 and ultimately culminated in the HiTOP structure (Kotov et al., 2017, 2021). This system offers an alternative to extant psychiatric taxonomies, being based largely in individual differences derived from a quantitative trait perspective. Running parallel to these efforts was the National Institute of Mental Health's Research Domain Criteria (RDoC; Insel et al., 2010), which, though fundamentally different in its emphasis on neural circuits and multimodal data identified by committee consensus, shares the perspective that individual differences in psychopathology could be understood in terms of a few basic dimensions or domains. One outlook on these developments is that the field is coming back to the view that personality and psychopathology should be integrated, albeit differently than in the middle of the $20^{\text {th }}$ century.

An assumption of models like HiTOP and RDoC is that the same dimensions can be used to describe individual differences in both normal-range functioning (i.e., personality) and psychopathology (DeYoung et al., this issue; Fournier et al., this issue). This assumption has been strongly influential on contemporary psychopathology research, much of which assumes or argues that personality and psychopathology share the same empirical space. There are significant scientific and clinical advantages to this point of view that have been articulated in a number of places (Conway et al., 2019; Hopwood et al., 2020; Ruggero et al., 2019; Waugh et 
al., 2017), including the articles of this Special Issue. Moreover, the body of work finding similarities between the structures of normative traits and maladaptive traits is vast and compelling (e.g., Gore \& Widiger, 2013; Markon et al., 2005; Morey et al., this issue; Thomas et al., 2013; Wright \& Simms, 2014). Even work that has sought differences between the two in extremity in shared trait-space would seem to be more supportive of overlap than uniqueness in the range of coverage of these domains (e.g., Samuel et al., 2010; Suzuki et al., 2015). As we see it, the behavioral scientist and the clinical psychologist/psychiatrist should share a fundamental understanding of the organization of behavior, in much the same way that the biologist and oncologist share the same understanding of the human cell. Shared models of typical and atypical functioning help organize findings and research agendas, linking seemingly disparate results and spurring more rapid accumulation of knowledge. This all may also lead to efficiencies in clinical assessment and treatment design and selection (Hopwood et al., 2020; Ruggero et al., 2019).

At the same time, there are also potential advantages to distinguishing personality from psychopathology. First, not distinguishing adaptive and maladaptive functioning contrasts with basic intuitions about human functioning, and what is plainly obvious even to lay observers, that some individuals experience periods of significant problems associated with their thoughts, feelings, and behaviors, whereas others do not. Second, it is arguably morally problematic to diagnose people based on their personality as opposed to clear evidence of dysfunction or impairment. For example, doing so puts the clinician in the position of telling their patient that they are the problem, as opposed to telling them that they have problems. Third, this is also a practical issue clinically, which is why the DSM includes not only a requirement for symptoms, which can be of ambiguous importance given the wide range of normative individual differences 
in behavior, but also a requirement for marked distress or dysfunction for diagnosis. Fourth, from a scientific perspective, the literature on shared structure of personality and psychopathology by design has sought similarities, but remained comparatively agnostic to that which might distinguish them. Though similarities are important in classification and understanding natural phenomena (e.g., vertebrates share important structural features), so too are differences (e.g., fish and fowl have evolved distinct features for success in different environments).

Despite the research supporting a shared conceptual and empirical space cited above, there is evidence for important differences when considering certain types of behavior. For instance, joint structural models struggle to explain behavior like self-harm (e.g., Markon et al., 2005; Wright \& Simms, 2014). In this issue, Morey et al. showed that conflating personality and psychopathology in the area of personality disorders can distort trait models, supporting the value of the DSM-5's Alternative Model of Personality Disorder in distinguishing between the two (see also Haigler \& Widiger [2001] for similar results). Longitudinal research suggests that individual differences in personality and individual differences in problems may follow a different temporal course (Wright, et al., 2016; Wright, Hopwood, \& Zanarini, 2015). Finally, Fournier et al. (this issue) emphasize differential responses to psychotherapy and medication for depression when it comes to personality and symptom measures.

In the next sections, we discuss how these issues interdigitate, highlighting how the authors of the Special Issue grappled with these challenges, and what we see as a necessary agenda for the way forward for developing comprehensive (i.e., integrated yet differentiated) models of personality and psychopathology.

\section{A Difficult Task}

So, how does contemporary psychological science view the value and promise of 
integrating personality and psychopathology? It is perhaps useful to elaborate how these concepts are currently represented in the literature, because there is some variation in how they are conceived and referenced (see also DeYoung et al., this issue). Doing so clarifies the typical foci of each domain, as well as points of overlap. Table 1 lists some of the terms that have been used to describe each domain, as well as some that have been used to refer to dimensions that span both of them. Reviewing these terms highlights, for instance, that personality has traditionally referred to what is typical of individuals, either in a statistical sense (e.g., normal, normative) between persons, or in the sense of what is characteristic of an individual's behavior. A common definition of personality is: one's characteristic pattern of motivations, thoughts, feelings, and behaviors. In contrast, psychopathology has emphasized what is atypical, either in the statistical sense (e.g., abnormal, atypical) between persons, or in terms of a departure from the individual's characteristic behavior. Another major distinction, which is more evident from the psychopathology terms, is that the construct refers to something that is not serving its intended purpose (dysfunction, maladaptive) or is impairing (disease, disorder, problem). That personality domains serve a functional purpose is evident to some degree (adaptive), but this is often implicit or assumed as opposed to being fully elaborated. However, the term "individual differences" stands out in the personality domain as almost definitional of the approach. Personality assumes that in some important ways individuals differ from each other. This has not always been assumed in psychopathology, which has tended to view mental disorders as singular entities reflecting more or less the same instantiation across individuals, though with some variation in its expression (e.g., polythetic symptom sets). However, this is changing to some degree. In the combined cell of the table, we list a number of terms that straddle personality and psychopathology. These terms are used in various ways by different authors, and it is not always 
clear what the assumptions of the terms are. In particular, are dimensional conceptualizations of psychopathology unipolar or bipolar? Are those low on the dimension presumed to be absent the features (i.e., the features are distinct from typical functioning), are they presumed to be healthy in the affected domain (i.e., is there only one problematic pole), or is the dimension assumed to be continuous with adaptive range functioning (i.e., the extremity hypothesis)?

Despite some clear differences in emphasis, the terms in Table 1 that span personality and psychopathology hint at the fact that cleanly slicing or parsimoniously summarizing that which distinguishes the two domains is a difficult task. Indeed, even providing a comprehensive definition of psychopathology remains elusive, challenging philosophers of science (Stein et al., 2021; Zachar, 2014). Nevertheless, each of the contributors grappled with the four questions we introduced above. Here are the key take-home points of their reviews or studies.

Is there evidence that personality and psychopathology can be integrated? Not every author team directly answered this question, though with some inference we can say that this was largely answered in the affirmative. Perhaps the firmest assertion that personality and psychopathology share the same empirical space came from DeYoung and colleagues (this issue), who were writing from the perspective of the HiTOP Personality Workgroup. Several others, including Edershile (this issue), Hall et al. (this issue), Jackson and Beck (this issue), Morey et al. (this issue), and Perlstein and Waller (this issue) all essentially endorsed the same position either explicitly or tacitly. Fournier and colleagues (this issue) as well as Wilson and Olino (this issue) also suggested that personality and psychopathology can be organized within the same system, but largely frame this in the context of a shared set of underlying neurobiological systems, which is aligned more with an RDoC take on the issue. Finally, SauerZavala and colleagues (this issue) and Luyten and Fonagy (this issue) each emphasized the 
relevance of broad personality domains for psychopathology, but were quick to highlight that psychopathology requires something considerably more that isn't embedded in those domains.

If so, is integration important? The responses to this question were similar to the previous one, in that most author teams, to varying degrees, recognized the value of incorporating the domain structure of personality and psychopathology within an integrative model. There were some differences in focus, with some endorsing a more traditional psychometric structure a la HiTOP (e.g., Jackson \& Beck, this issue; DeYoung et al., this issue; Edershile, this issue; Morey et al., this issue), others endorsing something more clearly aligned with RDoC (e.g., Fournier et al., this issue; Wilson \& Olino, this issue), and others remaining more circumspect and listing both as reasonable exemplars of viable ecumenical structures (e.g., Hall et al., this issue; Luyten \& Fonagy, this issue; Pearlstein \& Waller, this issue).

Can personality and psychopathology be distinguished? Despite the wide support across authors for the fact that personality and psychopathology share an empirical structure or underpinnings, most teams also emphasized that this is only part of the story. Hewing closest to the notion that personality and psychopathology can largely be encompassed within the same structure were DeYoung and colleagues. Taking the perspective of the HiTOP system, DeYoung et al. argued that the major distinction between traits and symptoms was one of temporal duration. In essence, symptoms are typically understood as states, whereas traits, which can be either adaptive or maladaptive, are more enduring aspects of the individual. There was some recognition that certain constructs within psychopathology defy this neat classification, such as highly persistent but episodic phenomena, like manic episodes. Extending the structure of HiTOP to include temporal information about development, course, duration, and cyclicity must be a top priority as the consortium moves forward. However, two aspects of this response are 
notable in their departure from the evidence-based worldview that generally characterizes the HiTOP approach. First, DeYoung et al. seem to distinguish categorically between traits and symptoms/states, although it seems to us more likely that the timescale of behavioral process ranges from more to less stable in a continuous manner (Hopwood et al., in press). Second, though elegant in its parsimony, this argument, which was most central in the DeYoung paper, disengages from the question of what differentiates personality and psychopathology by focusing on features that could be either adaptive or maladaptive at different timescales. DeYoung et al. do acknowledge that clinical constructs require the presence of dysfunction, but their conceptualization of what dysfunction is and how it is different from personality is speculative rather than empirically based. This need to rely on supposition as opposed to evidence, from a group founded on quantitative epistemology, highlights how far the field has to go in answering this challenging question.

Wilson and Olino (this issue), in taking a developmental perspective, suggested that although in theory personality and psychopathology were distinct, due to various reciprocal processes across the course of development, they are likely to become, through mutual influence, largely indistinguishable by adulthood. In other words, personality often confers risk for psychopathology and psychopathology often becomes embedded in one's personality in turn. This perspective offers a more nuanced view of any potential isomorphism. Also adopting a developmental perspective, Luyten and Fonagy (this issue) argue that psychopathology is fundamentally an expression of functional adaptation that comes about to deal with important tasks of living, but that it becomes problematic through a shift in context (e.g., developmental stage or environment) if the individual fails to change their strategy. They also offered the interesting hypothesis that the degree of psychopathology severity is relevant for how 
intertwined it is with personality, with greater severity (e.g., multiple disorders) more strongly representative of personality whereas more circumscribed or transient disorders are not necessarily reflective of personality. Likewise, Edershile (this issue) argued that the distinction between personality and psychopathology emerges in functional contexts in the (mis)match between an individual's goals and their efforts to enact them, particularly within interpersonal situations. Hall and colleagues (this issue) draw essentially the same distinction, but do so in reference to decision making and cognitive control. Relevant to each of these perspectives, Pearlstein and Waller (this issue) argue that the more pressing need is to distinguish the individual and context, and each of their relative contributions to functioning.

Other authors emphasized the importance of some sort of distinction between personality and pathology, sometimes suggesting a construct that explained (at least part of) the difference. For instance, Fournier and colleagues (this issue) emphasized the differences in response to psychotherapy between personality and psychopathology, and the need to return to the basics of neurobiology to adjudicate between the two. Sauer-Zavala and colleagues (this issue) argue for a functional bridge that accounts for the difference between the adaptive and maladaptive manifestations of the personality and psychopathology domains. They emphasize neuroticism and emotional avoidance, but suggest plausible links for all big five domains.

How can the differences between personality and psychopathology be measured? This final question was by far the most difficult, as well as the one most open to philosophical and theoretical differences. Not surprisingly, it garnered the most diverse responses. In their empirical study, Morey and colleagues (this issue) showed that once general dysfunction is adjusted for, maladaptive and adaptive traits show stronger convergent and divergent associations with each other. This study highlights how the failure to account for differences 
between personality and psychopathology can actually distort basic models of individual differences as applied to clinical constructs. This point was echoed in the Luyten and Fonagy (this issue) paper, who argued that as general levels of psychopathology increase, it is more difficult to distinguish from personality. DeYoung offered relatively direct guidance about the measurement approaches that would be required to distinguish personality from psychopathology, and noted that the HiTOP measurement group are working on this as this issue goes to press (Simms et al., in press), although in practice this remains aspirational.

The remainder of the papers generally made recommendations for future research programs, but not for direct clinical assessment. For instance, Fournier and colleagues (this issue) essentially take the position that to distinguish between what existing measures of personality and psychopathology capture, one must have an external vantage point for comparison, and they promote neurobiology for this purpose. But these protocols to date are unwieldy and lack direct clinical relevance. By the same token, Edershile (this issue) and Hall et al. (this issue) suggest that there is value in using decision making and behavioral tasks to extract dynamic parameters of performance, but these approaches are also not ready for applied implementation. Pearlstein and Waller (this issue) suggest that genetically informed studies that include systematic assessment of the environment are necessary, and recommend recently developed taxonomies are needed, including DIAMONDs (Rauthmann et al., 2014) and CAPTION (Parrigon et al., 2017). Finally, both Wilson and Olino (this issue) and Luyten and Fonagy (this issue) implore the field to invest more in longitudinal, developmentally informed studies.

Taken as a whole, the contributions highlight that the seemingly straightforward questions of whether and how people and their problems are related and how they are different 
are actually exceptionally complex and difficult to answer. The contributions also demonstrate that these are highly multi-faceted questions, and there are many ways to approach them, each with its own promise and challenges. Whereas most author teams seemed inclined to acknowledge core similarities between personality and psychopathology within each individual differences (e.g., big five) domain, many were also quick to say this wasn't the whole story. We see a great deal of value in the differing perspectives, and many emphases, including the role of measurement, temporal course, development, incorporating the role of the environment, and distinguishing content from process. Dealing with these issues is critical for any model that seeks to comprehensively integrate personality and psychopathology. In the remaining sections, we attempt to integrate and summarize the authors' contributions by articulating the five major tasks - and associated challenges - required to generate a comprehensive and functional model of personality and psychopathology.

\section{Toward a Functional Model}

Looking across the papers of the Special Issue, we see a rich plurality of perspectives. On the one hand, that so many scholars are taking this question seriously is encouraging, and each has important contributions to make. One the other hand, it reveals that there are many pieces to this puzzle, and they will be challenging to fit together. With the benefit of having edited each of these manuscripts, we can say that every author team struggled to one degree or another with the task of answering these four questions. No perspective offers a complete, evidence-based model at this time. That's not criticism. It's a reflection of how challenging this task is, and we've sweated under the same load in our own writing (e.g., Hopwood, 2018; Hopwood, Wright, \& Bleidorn, 2021; Wright \& Kaurin, 2020; Wright, Pincus, \& Hopwood, 2021). Personality science focuses on the whole individual, and personality psychologists generally are not satisfied with 
biological reductionism, rigid environmentalism, or a narrow focus on motivations, thoughts, feelings, or behavior - it is about how all of these deeply multisystemic domains come together within an individual across time and context, and how individuals differ from each other in important ways. Psychopathology similarly touches virtually all aspects of the human condition, and from a personality perspective, is best understood within a whole-person perspective. That is why achieving an integrative model is so difficult. But doing so holds considerable promise for furthering our understanding of human nature and promoting public health.

If one limits the scope of this problem to the structure of individual differences in personality and psychopathology as assessed with questionnaires at one point in time, the task seems relatively simple. As DeYoung et al. (this issue) reviewed (see also Kotov et al. [2021] and Widiger et al. [2019]), the structures are remarkably well aligned at the level of broad domains or spectra. Virtually all the Special Issue manuscripts endorsed this view to some degree, and we find this assertion compelling too. To the extent that the psychometric tradition has served to identify important domains of psychological functioning, it would only make sense that adaptive and maladaptive functioning would share the same set of domains (Leary, 1957; Wright \& Simms, 2015). At the same time, this observation remains descriptive and nomothetic, and by itself provides no guidance on how to think about what distinguishes the person from the person's problems, let alone a plausible mechanism that might do so, for a particular patient.

In contrast, not every author team hazarded an explanation for what differentiated personality and psychopathology, but those who did consistently identified the main difference between the two being functional vs. dysfunctional engagement of the processes underlying the domains relative to some external criterion. In other words, there was general recognition that the domains mapped by structural models reflect functional systems evolved to deal with major life 
tasks (e.g., Harkness et al., 2014). From that frame of reference, psychopathology, though maybe not exclusively, refers to instances when pursuit of those tasks is not effective or is disrupted. We agree, and wish to highlight some implications of this point and offer five recommendations for future work on the relationship between personality and psychopathology, which are summarized in Table 2.

First, neither personality nor psychopathology can be defined without a referent, and as such essentially implies a person-by-environment transaction (Hopwood et al., 2021; Pearlstein \& Waller, this issue). That is, some context is necessary to know whether the individual's thoughts, feelings, or behaviors are functional or dysfunctional or not. It is true that, at extreme levels, dysfunction can be explained largely in terms of the person or in terms of the environment. It is easy to think of cases, the severe disorganization of some psychotic states for example, where an individual's psychological make up is so disordered that virtually any situation will elicit dysfunctional behavior. Individuals with extreme developmental disabilities may be also unlikely to thrive, at least according to conventional ideas about thriving, regardless of the environment they are in. It is also easy to think of contexts that would impair, either through distress or dysfunction, all but the most statistically exceptional individuals (Frankl, 1946; May, 1950). Chronic economic despair, abuse, and severe social persecution come to mind. However, even here, one can think of exceptions, and the more common situation is that psychopathology is evident in the transaction between the person and their environment.

Acknowledging the context-dependent nature of personality and psychopathology is necessary to explain why personality trait extremity is not synonymous with dysfunction. To the extent that individuals very high, even extreme, in some domains can effectively channel their personality and modulate it, when necessary, they should not be assumed to be dysfunctional. To 
the extent that someone with a moderate level of a trait consistently mismatch their goals and behaviors to demands of situations, their behavior should be considered dysfunctional. For instance, a person with impulsive and sensation-seeking personality traits may find themselves habitually in situations in which they find trouble, because they tend to seek them out. There are also cases in which a person finds themselves in an environment that is simply not a good fit for them, in the absence of selection processes. For instance, a person with a highly unconventional and antagonistic personality may do well in certain cultures, but are less likely to adapt if born into a highly conventional and conformist society. Or as another example, a person with depressive and dependent tendencies in a family environment that promotes individualism and self-reliance may feel alone and incapable, even if they might have done well in a more supportive and inclusive family.

Some may raise the objection that hypothetically, trait extremity may have some adaptive functioning in some contexts, but maladaptive in others (e.g., the workaholic captain of industry whose relationships all fare poorly). This is a reasonable critique, but to date this proposition has insufficient support and would require more person-centered research that seeks to study the individual as they function across relevant contexts. One would need to show that the same individual who excels in one domain is also failing in another for reasons having to do with the same trait, and cross-sectional patterns of covariance are insufficient to this task. Further, to the extent that extremity is related to dysfunction, our strong hypothesis is that this kind of process would still be mediated through a person-by-situation transaction, such that the extreme individual is more rigid or narrow in their behavioral repertoire thereby impairing their ability to appropriately shift as the situation calls for it. Thus, we see as the first major recommendation emerging from this point that research needs to consistently and meaningfully incorporate 
context into its design (see Table 2). In particular, designs are needed that can differentiate between plausible person-by-context interactions, such as situation selection, evocation, and reaction (see Hopwood and friends [2021] for elaboration). Pearlstein and Waller (this issue) elaborate these points considerably, and Edershile (this issue) and Hall et al. (this issue)'s proposals can also be understood as reflections of this point.

Second, and closely related, differentiating personality and psychopathology generally requires mapping their temporal course. As DeYoung and colleagues (this issue) note, though traits and symptoms (i.e., maladaptive states) might be distinguished based on duration, personality and psychopathology cannot, because each manifest in states, traits, and everything in between. That notwithstanding, there are several reasons temporal course is important for distinguishing personality and psychopathology. In part, because context varies over time, to distinguish context from the individual one has to repeatedly assess them both. Another reason is conceptual, in that there are very few thoughts, feelings, or behaviors that, when exhibited once or for short periods are reflective of dysfunction. People make mistakes, they try things out, they misperceive a situation and respond to their construal as opposed to the actual situation, and so on, but these missteps generally get quickly corrected. Moreover, many costly behaviors serve a corrective role in altering our behavior and keeping us from maladaptation in the long run. Indeed, this is a feature, not a bug, of an adaptive system (Carver \& Scheier, 1998; DeYoung, 2015). Only when a behavior is sustained for some duration (which likely varies by specific behavior) despite opportunities for correction can it be understood to be a maladaptation or dysfunction (Kelly, 1955; Loevinger, 1966). This importance of temporal course is represented in the DSM's disorder criteria, which generally require some minimal temporal duration. For instance, depressive episodes must be of two weeks in length, uncontrollable worry must be 
present for six months or more, and so forth. Though the DSM's particular temporal durations lack any empirical basis, their necessity is undeniable. Without them it would be very difficult to distinguish transient or even natural adaptive processes from disorder.

Another way in which temporal course manifests is in development, in that most behaviors that comprise psychopathology follow normative developmental courses (Wilson \& Olino, this issue). Failure to achieve expected levels of maturation, which generally refers to the ability to satisfactorily fulfill major social expectations, is often a marker of psychopathology. Many behaviors are expected or of little concern early in development, but become meaningful markers of psychopathology if the same behavior is expressed at a later point in development. Psychopathology may be reflected in developmental delays or stagnation. Accelerated development may be less likely to reflect psychopathology per se, but it often places youths at risk for it (Hamlatt et al., 2019; Patton et al., 2004). Thus, very generically, to distinguish between normative and dysfunctional, one usually needs to know not just which behaviors are involved, but when in development they are present. Wilson and Olino (this issue) further outline how personality and psychopathology likely each influence the other in complex ways throughout development. Extending this point, Luyten and Fonagy (this issue) highlight that in many cases, what we perceive as maladaptive or dysfunctional is precisely the lingering residue of prior adaptation to a specific and possibly pathological situation. Ironically, one's ability to adapt in self-protective ways to a harsh environment early in life (e.g., unpredictable and punitive parents) may leave them vulnerable to difficulties navigating less extreme environments later (e.g., typical caring adult relationships; Benjamin, 1993). Moving forward, we believe there are decreasing returns for understanding the association between personality and psychopathology using cross-sectional methods, and recommend prioritizing investments in 
longitudinal research at different time scales from the micro (seconds and below) to the macroscale (years to decades).

Third, defining and understanding functioning implies shifting from descriptive domains to explanatory processes, and likely implies "third variables" not currently part of structural models of personality and psychopathology. For instance, Fournier et al. (this issue) explicitly named neurobiological circuits as their preferred arbiter. Edershile (this issue) suggested that the differences might be revealed in the economic decisions and negotiations of game tasks, whereas Hall et al. (this issue) instead emphasized cognitive control. The psychometric tradition has taken us very far in both personality and psychopathology, but its traditional reliance on uni-modal measurement is likely placing an asymptote on our knowledge, and muddying the waters as we seek to look further into the depths of their relationship. This is, in part, because the most extensively validated measurement approaches - self-report and interview scales - appear to lack sufficient sensitivity. Even our best designed measures are finely-tuned blunt instruments. In fact, as it stands now, measures of normal range and maladaptive personality each appear to be largely overlapping in their information (e.g., Samuel et al., 2010; Suzuki et al., 2015), and in the process they tend to blend content and functioning (see also Clark \& Ro, 2014; and Ro \& Clark, 2009, 2013). Part of the reason these are difficult to disentangle is that basic personality traits are not functionally neutral, at least not as it relates to the situations most individuals are most likely to encounter in most societies. So, for instance, being more interpersonally engaged tends to confer better functioning on average, and being withdrawn tends to conduce to more difficulties on average. However, part of the reason is in how the questionnaire items are written and measures are developed. Morey and colleagues (this issue) demonstrated this point by examining the raw and adjusted associations among personality traits, maladaptive traits, and a dysfunction 
measure in a large community sample. DeYoung et al. (this issue) also gave examples of questions that did and did not blend personality content and dysfunction. Jackson and Beck (this issue) perhaps exemplified the issue the best in trying to somewhat arbitrarily distinguish between those indicators that were "personality" and which were "psychopathology." Ideally dysfunction and domains in which they manifest would be measured separately, and though this is very challenging empirically (Clark \& Ro, 2014; Ro \& Clark, 2013), we recommend future work attend to this issue when designing protocols (see Table 2).

Beyond this, a key reason existing measures lack sensitivity is that they generally smooth over contexts and temporal course in their administration, asking individuals to report on how they typically behave or behaved over a particular period of time. Therefore, responses largely reflect individual differences, but specifically are designed (in most cases) to exclude personsituation transactions. Our measures are built on notions of latent variables, such that the questionnaire responses are outcomes of someone's personality or psychopathology, not the actual process of interest itself. For instance, endorsing the DSM's perceived abandonment criterion for borderline personality disorder, negative and positive urgency (Cyders \& Smith, 2008; Whiteside \& Lynam, 2001) and narcissistic vulnerability (Pincus et al., 2009) each describe contextual processes. Yet, accumulating research suggests that each might "collapse into" broader dispositional negative affectivity (Miller et al., 2018; Simms et al., 2011). Perhaps this is because these hypothesized processes are illusory, or, more plausibly, it is because dispositional scales lack the necessary sensitivity to sample dynamic, context dependent processes (Edershile \& Wright, in press, 2021; Sperry et al., 2021). Scores on our best-validated tools can be interpreted as a summary of the (directly) unobserved processes that drive, for instance, neuroticism, also manifest in panic disorder, social phobia, and depressive episodes. 
But they leave open the question of why one person experiences panic attacks and another phobias, why one person is phobic of spiders and another of elevators, why they each experienced them last year but not this year, and so forth. Those sorts of questions are scientifically and clinically important, and they have direct relevance for intervention (SauerZavala et al., this issue).

There are other notable issues with self-report inventories and interviews related to potential biases and blind-spots, or limitations in self-awareness and willingness to disclose, of the individual reporting the information. It is now clear that no one person has the full picture of an individual's personality and psychopathology, and instead different vantage points favor different perspectives, each of which is to some degree overlapping with the others, but also distinct while still being valid (Vazire, 2010). Research shows that other-reported personality is moderately to strongly correlated with self-report scores (Kim et al., 2019), but also has important incremental predictive validity for a variety of important life outcomes (Beer \& Vazire, 2017; Connelly \& Ones, 2010; Fiedler et al., 2004; Samuel et al., 2013; Thielmann et al, 2017). Thus, a full picture of personality requires more than just the individual's own perspective. This issue also appears related to the lack of sensitivity we describe above, in that evidence seems to point to greater differentiation among multi-informant rated personality traits than self-report only (Anusic et al., 2009; DeYoung, 2006; Leising et al., 2010; McCrae et al., 2008).

Two implications follow, which represent the fourth and fifth innovations we perceive necessary in research on personality and psychopathology (see Table 2). The fourth is that we need to increase our use of multimodal data that is well-suited to sampling diverse aspects of functional processes, and decrease the field's reliance on self- and interview-reported 
information in order to move forward (Bornstein, 2009; Edershile, this issue; Fournier, this issue). Edershile suggests that there is potentially a good deal of gold in the hills of economic game tasks. However, she notes that the traditional approach of collapsing across iterations or exchanges in situations leads to individual difference scores that suffer from all the limitations and ambiguities or questionnaires (i.e., smoothing over contextualized processes). She therefore argues for adopting a computational approach that leverages the dynamic contextual information contained in the dynamics of the iterative transactions within each task and compares processes across relevant tasks. Hall and colleagues (this issue) argue for a similar approach. Fournier's team (this issue) favors the RDoC's emphasis on neural circuitry. Though the RDoC approach is also explicitly multi-modal, such that RDoC projects must measure constructs across "units" of analysis. Though we want to echo these calls and push the field in this direction, there are significant difficulties associated with the basic measurement in multimodal data. Specifically, the psychometrics of many tasks has been questioned or remains understudied (Dang et al., 2020; Hedge et al., 2018), and method specific variance can easily overwhelm trait variance (e.g., Kaurin et al., in press).

The fifth and final implication is that we need to discontinue the tacit assumption that nomothetic principles apply to individual cases. This needn't be the case (Molenaar, 2004), and an accumulating body of work using idiographic (i.e., personalized or person-specific) models suggests it rarely is (Wright et al., 2019), even among individuals with the same diagnosis (e.g., Fisher et al., 2017; Woods et al., 2020). This was the focus of the Beck and Jackson (this issue) paper, in which the authors showed that different combinations of traits were related to psychopathological symptoms for different individuals. Idiographic models require intensive within-person data, which can be used to test the degree to which nomothetic principles apply to 
individual cases (Wright \& Zimmermann, 2019). It is possible that, whereas being too disagreeable leads to interpersonal conflict for most people, for some patients, the tendency to be too agreeable is actually the stimulus for criticism and resentment. It is notable that clinicians are generally more interested in the question of how a particular person's problems function, and would naturally prioritize person-specific functional formulations over nomothetic covariance structures. This example, and the accumulating idiographic research, puts a fine point on the issue we raised above, namely that extremity in a given personality domain cannot be equivalent with dysfunction even if it is probabilistically so. One way around this probabilistic and descriptive approach to studying pathological processes is to use idiographic modeling to identify individuals who specifically exhibit a process, and study them. This is not the way most longitudinal designs currently function. They primarily look at how dispositional scales moderate within-person behavior-by-situation interactions, which is a decidedly limited approach because it prioritizes an approximation of as opposed to direct measurement of the process of interest. By using idiographic models to identify those exhibiting a specific dysfunctional process, greater precision can be achieved in understanding those processes.

Thus, part of bridging science and practice has to do with modeling the problems as they occur in the lives of real people, which in many cases will involve idiographic patterns that do not follow from group-based, nomothetic models. That being said, like with multimodal data, idiographic or personalized models of personality and psychopathology need considerable conceptual and methodological work (Wright \& Woods, 2020; Wright \& Zimmermann, 2019).

\section{Conclusion}

The pendulum has swung from thinking about personality and psychopathology within an integrated psychoanalytic system, to separating them by way of the DSM-III, to putting them 
back together again in models like HiTOP or RDoC. Though most papers in the Special Issue highlighted the need to differentiate personality and psychopathology, we believe that in the context of these swings, we are getting closer to the truth. Just as the HiTOP and RDoC models are built on a firmer empirical basis than was early psychoanalytic theory, ongoing efforts to figure out the difference between personality and psychopathology should be rooted in more principled and evidence-based models than that of the contemporary DSM era (i.e., DSM-III through DSM-5). Diagnostic manuals should reflect our understanding of psychological functioning and its dysfunction, not dictate how we understand it.

Being on stronger empirical footing that unambiguously shows the convergence between individual differences in personality and psychopathology, the time is right to do the hard work of developing comprehensive integrative models that explicitly incorporate functional definitions of both. This is the next horizon for personality and psychopathology research. This process is afloat, with contributions advancing into various waters. We see each of the papers of this Special Issue riding this general swell. In addition, there are those from personality and clinical sciences charting a tack towards theoretical models that seek to integrate dispositions, development, and dynamics (e.g., Baumert et al., 2017; Wright et al., 2021; Wruz \& Roberts, 2017). To these efforts we add our five recommendations in the hopes they inspire more forward-thinking research that can dredge channels between personality and psychopathology as well as basic and applied behavioral sciences. 


\section{References}

**Special Issue Paper

American Psychiatric Association. (1952). The diagnostic and statistical manual of mental disorders. Author.

American Psychiatric Association. (1968). The diagnostic and statistical manual of mental disorders, $2^{\text {nd }}$ Edition. Author.

American Psychiatric Association. (1980). The diagnostic and statistical manual of mental disorders, $3^{\text {rd }}$ Edition. Author.

American Psychiatric Association. (2013). The diagnostic and statistical manual of mental disorders, 5th Edition. Author.

Anusic, I., Schimmack, U., Pinkus, R. T., \& Lockwood, P. (2009). The nature and structure of correlations among Big Five ratings: The Halo-Alpha-Beta model. Journal of Personality and Social Psychology, 97, 1142-1156.

Baumert, A., Schmitt, M., Perugini, M., Johnson, W., Blum, G., Borkenau, P., ... \& Mõttus, R. (2017). Integrating personality structure, personality process, and personality development. European Journal of Personality, 31(5), 503-528.

Beer, A., \& Vazire, S. (2017). Evaluating the predictive validity of personality trait judgments using a naturalistic behavioral criterion: a preliminary test of the self-other knowledge asymmetry model. Journal of Research in Personality, 70, 107-121.

Connelly, B. S., \& Ones, D. S. (2010). An other perspective on personality: Meta-analytic integration of observers' accuracy and predictive validity. Psychological Bulletin, 136(6), $1092-1122$.

Benjamin, L. (1993). Every psychopathology is a gift of love. Psychotherapy research, 3(1), 1- 
24.

Bornstein, R. F. (2009). Heisenberg, Kandinsky, and the heteromethod convergence problem: Lessons from within and beyond psychology. Journal of Personality Assessment, 91(1), $1-8$.

Carver, C., \& Scheier, M. (1998). On the self-regulation of behavior. New York: Cambridge University Press.

Clark, L. A., \& Ro, E. (2014). Three-pronged assessment and diagnosis of personality disorder and its consequences: Personality functioning, pathological traits, and psychosocial disability. Personality Disorders: Theory, Research, and Treatment, 5(1), 55-69.

Conway, C.C., Forbes, M.K., Forbush, K.T., Fried, E.I., Hallquist, M.N., Kotov, R., MullinsSweatt, S.N., Shackman, A.J., Skodol, A.E., South, S.C., Sunderland, M., Waszczuk, M.A., Zald, D.H., Afzali, M. H., Bornovalova, M.A., Carragher, N., Docherty, A.R., Jonas, K.G., Krueger, R.F., Patalay, P., Pincus, A.L., Tackett, J.L., Reininghaus, U., Waldman, I.D., Wright, A.G.C., Zimmermann, J., Bach, B., Bagby, R.M., Chmielewski, M., Cicero, D.C., Clark, L.A., Dalgleish, T., DeYoung, C.G., Hopwood, C.J., Ivanova, M.Y., Latzman, R.D., Patrick, C.J., Ruggero, C.J., Samuel, D.B., Watson, D., \& Eaton, N.R. (2019). A hierarchical taxonomy of psychopathology can transform mental health research. Perspectives on Psychological Science, 14(3), 419-436.

Dalgleish, T., Black, M., Johnston, D., \& Bevan, A. (2020). Transdiagnostic approaches to mental health problems: Current status and future directions. Journal of consulting and clinical psychology, 88(3), 179.

Dang, J., King, K. M., \& Inzlicht, M. (2020). Why are self-report and behavioral measures weakly correlated?. Trends in cognitive sciences, 24(4), 267-269. 
DeYoung, C. G. (2006). Higher-order factors of the Big Five in a multi-informant sample. Journal of Personality and Social Psychology, 91, 1138-1151.

DeYoung, C. G. (2015). Cybernetic big five theory. Journal of research in personality, 56, 3358.

**DeYoung, C.G., Chmielewski, M., Clark, L.A., Condon, D.M., Kotov, R., Krueger, R.F., Lynam, D.R., Markon, K.E., Miller, J.D., Mullins-Sweatt, S.N., Samuel, D.B., Sellbom, M., South, S.C., Thomas, K.M., Watson, D., Watts, A.L., Widiger, T.A., Wright, A.G.C., \& the HiTOP Normal Personality Workgroup. (in press). The distinction between symptoms and traits in the Hierarchical Taxonomy of Psychopathology (HiTOP). Journal of Personality.

Digman, J. M. (1990). Personality structure: Emergence of the five-factor model. Annual review of psychology, 41(1), 417-440.

**Edershile, E.A. (in press). Leveraging Economic Games to Integrate and Differentiate Personality and Psychopathology. Journal of Personality.

Edershile, E.A., \& Wright, A.G.C. (in press). Fluctuations in grandiose and vulnerable narcissistic states: A momentary perspective. Journal of Personality and Social Psychology. https://psyarxiv.com/8gkpm/

Edershile, E.A., \& Wright, A.G.C. (2021). Narcissism dynamics. Manuscript submitted for publication.

Fiedler, E. R., Oltmanns, T. F., \& Turkheimer, E. (2004). Traits associated with personality disorders and adjustment to military life: Predictive validity of self and peer reports. Military medicine, 169(3), 207-211.

Fisher, A. J., Reeves, J. W., Lawyer, G., Medaglia, J. D., \& Rubel, J. A. (2017). Exploring the 
idiographic dynamics of mood and anxiety via network analysis. Journal of abnormal psychology, 126(8), 1044.

**Fournier, J. C., Roberts, N. J., \& Ford, K. L. (in press). Personality and psychopathology: In defense of a practical path toward integrating psychometric and biological approaches to advance a comprehensive model. Journal of Personality.

Frankl, V. E. (1946). Man's search for meaning. Simon and Schuster.

Goldberg, L. R. (1990). An Alternative" Description of Personality": The Big-Five Factor Structure. Journal of Personality, 59(6), 1216-1229.

Gore, W. L., \& Widiger, T. A. (2013). The DSM-5 dimensional trait model and five-factor models of general personality. Journal of abnormal psychology, 122(3), 816.

Haigler, E. D., \& Widiger, T. A. (2001). Experimental manipulation of NEO-PI-R items. Journal of Personality Assessment, 77(2), 339-358.

**Hall, N., Schreiber, A., Allen, T., \& Hallquist, M. (in press). Disentangling cognitive processes in externalizing psychopathology using drift diffusion modeling: Antagonism, but not Disinhibition, is associated with inhibitory control deficits. Journal of Personality.

Harkness, A. R., Reynolds, S. M., \& Lilienfeld, S. O. (2014). A review of systems for psychology and psychiatry: Adaptive systems, personality psychopathology five (PSY5), and the DSM-5. Journal of personality assessment, 96(2), 121-139.

Hamlat, E. J., Snyder, H. R., Young, J. F., \& Hankin, B. L. (2019). Pubertal timing as a transdiagnostic risk for psychopathology in youth. Clinical Psychological Science, 7(3), 411-429.

Harris, R. E., et al. (1950). Recent advances in diagnostic psychological testing; a critical 
summary. C. C. Thomas.

Hedge, C., Powell, G., \& Sumner, P. (2018). The reliability paradox: Why robust cognitive tasks do not produce reliable individual differences. Behavior research methods, 50(3), 11661186.

Hopwood, C. J., (2018). Interpersonal dynamics in personality and personality disorders. European Journal of Personality, 32(5), 499-524.

Hopwood, C. J., Bagby, R. M., Gralnick, T., Ro, E., Ruggero, C., Mullins-Sweatt, S., ... \& Zimmermann, J. (2020). Integrating psychotherapy with the hierarchical taxonomy of psychopathology (HiTOP). Journal of Psychotherapy Integration, 30(4), 477.

Hopwood, C.J., Bleidorn, W., \& Wright, A.G.C. (in press). Getting the timing right in longitudinal research. Perspectives on Psychological Science.

Hopwood, C.J., Wright, A.G.C., \& Bleidorn, W. (2021). Distinguishing personality and psychopathology. Manuscript submitted for publication.

Insel, T. R., Cuthbert, B. N., Garvey, M. A., Heinssen, R. K., \& Pine, D. S. (2010). Research Domain Criteria (RDoC): Toward a New Classification Framework for Research on Mental Disorders. Am J Psychiatry, 167(7), 748-751.

**Jackson, J. J., \& Beck, E. D. (in press). Using idiographic models to distinguish personality and psychopathology. Journal of Personality.

Kaurin, A., Sequeira, S.L., Ladouceur, C.D., McKone, K.M.P., Rosen, D., Jones, N., Wright, A.G.C., \& Silk, J.S. (in press). Modeling sensitivity to social threat in adolescent girls: A psychoneurometric approach. Journal of Abnormal Psychology.

\section{https://psyarxiv.com/489k3/}

Kelly, G.A. (1955). The Psychology of Personal Constructs. Norton. 
Kim, H., Di Domenico, S. I., \& Connelly, B. S. (2019). Self-other agreement in personality reports: A meta-analytic comparison of self-and informant-report means. Psychological science, 30(1), 129-138.

Kotov, R., Gamez, W., Schmidt, F., \& Watson, D. (2010). Linking “big” personality traits to anxiety, depressive, and substance use disorders: a meta-analysis. Psychological bulletin, 136(5), 768.

Kotov, R., Krueger, R.F., Watson, D., Achenbach, T.M., Althoff, R.R., Bagby, M., Brown, T.A., Carpenter, W.T., Caspi, A., Clark, L.A., Eaton, N.R., Forbes, M.K., Forbush, K.T., Goldberg, D., Hasin, D., Hyman, S.E., Ivanova, M.Y., Lynam D.R., Markon, K., Miller, J.D., Moffitt, T.E., Morey, L.C., Ormel, J., Patrick, C.J., Regier, D.A., Rescorla, L., Robinson, E., Ruggero C.J., Samuel, D.B., Sellbom, M., Simms, L.J., Skodol, A.E., Slade, T., South, S.C., Tackett, J.L., Waldman, I.D., Widiger, T.A., Wright, A.G.C., \& Zimmerman, M. (2017). The Hierarchical Taxonomy of Psychopathology (HiTOP): A dimensional alternative to traditional nosologies. Journal of Abnormal Psychology, 126(4), 454-477.

Kotov, R., Krueger, R.F., Watson, D., Cicero, D.C., Conway, C.C., DeYoung, C.G., Eaton, N.R., Forbes, M.K., Hallquist, M.N., Latzman, R.D., Mullins-Sweatt, S.N., Ruggero, C.J., Simms, L.J., Waldman, I.D., Waszczuk, M.A., \& Wright, A.G.C. (2021). The Hierarchical Taxonomy Of Psychopathology (HiTOP): A quantitative nosology based on consensus of evidence. Annual Review of Clinical Psychology, 17, 83-108

Krueger, R. F. (1999). The structure of common mental disorders. Archives of general psychiatry, 56(10), 921-926.

Krueger, R. F., Caspi, A., Moffitt, T. E., \& Silva, P. A. (1998). The structure and stability of 
common mental disorders (DSM-III-R): a longitudinal-epidemiological study. Journal of abnormal psychology, 107(2), 216.

Krueger, R. F., Skodol, A. E., Livesley, W. J., Shrout, P. E., \& Huang, Y. (2007). Synthesizing dimensional and categorical approaches to personality disorders: refining the research agenda for DSM-V Axis II. International Journal of Methods in Psychiatric Research, 16(S1), S65-S73.

Leary, T. (1957). Interpersonal diagnosis of personality: A functional theory and methodology for personality evaluation. Ronald Press.

Leising, D., Erbs, J., \& Fritz, U. (2010). The letter of recommendation effect in informant ratings of personality. Journal of personality and social psychology, 98(4), 668.

Loevinger, J. (1966). Three principles for a psychoanalytic psychology. Journal of Abnormal Psychology, 71(6), 432-443.

**Luyten, P., \& Fonagy, P. (in press). Integrating and differentiating personality and psychopathology: A psychodynamic perspective. Journal of Personality.

Markon, K. E., Krueger, R. F., \& Watson, D. (2005). Delineating the structure of normal and abnormal personality: an integrative hierarchical approach. Journal of personality and social psychology, 88(1), 139.

May, R. (1950). The meaning of anxiety. WW Norton \& Company.

McCrae, R. R., Yamagata, S., Jang, K. L., Riemann, R., Ando, J., Ono, Y., et al. (2008). Substance and artifact in the higher-order factors of the Big Five. Journal of Personality and Social Psychology, 95, 442-455.

Miller, J. D., Lynam, D. R., Vize, C., Crowe, M., Sleep, C., Maples-Keller, J. L., ... \& Campbell, W. K. (2018). Vulnerable narcissism is (mostly) a disorder of neuroticism. Journal of 
personality, 86(2), 186-199.

Molenaar, P. C. (2004). A manifesto on psychology as idiographic science: Bringing the person back into scientific psychology, this time forever. Measurement, 2(4), 201-218.

**Morey, L. C., Good, E. W., \& Hopwood, C. J. (in press). Global personality dysfunction and the relationship of pathological and normal trait domains in the DSM-5 alternative model for personality disorders. Journal of Personality.

Mõttus, R., Wood, D., Condon, D. M., Back, M., Baumert, A., Costantini, G., Epskamp, S., Greiff, S. Johnson, W., Lukaszewski, A., Murray, A., Revelle, W., Wright, A.G.C., Yarkoni, T., Ziegler, M., \& Zimmermann, J. (2020). Descriptive, predictive and explanatory personality research: Different goals, different approaches, but a shared need to move beyond the Big Few traits. European Journal of Personality, 34, 1175-1201. https://doi.org/10.31234/osf.io/hvk5p

Mulay, A. L., Cain, N. M., Waugh, M. H., Hopwood, C. J., Adler, J. M., Garcia, D. J., ... \& Skadberg, R. (2018). Personality constructs and paradigms in the alternative DSM-5 model of personality disorder. Journal of personality assessment, 100(6), 593-602.

Parrigon, S., Woo, S. E., Tay, L., \& Wang, T. (2017). CAPTION-ing the situation: A lexicallyderived taxonomy of psychological situation characteristics. Journal of Personality and Social Psychology, 112(4), 642-681.

Patton, G. C., McMorris, B. J., Toumbourou, J. W., Hemphill, S. A., Donath, S., \& Catalano, R. F. (2004). Puberty and the onset of substance use and abuse. Pediatrics, 114(3), e300e306.

**Perlstein, S., \& Waller, R. (in press). Integrating the study of personality and psychopathology in the context of gene-environment correlations across development. Journal of 


\section{Personality.}

Rapaport, D., Gill, M., \& Schafer, R. (1946). Diagnostic psychological testing: The theory, statistical evaluation, and diagnostic application of a battery of tests: Vol. 2. The Year Book Publishers.

Rauthmann, J. F., Gallardo-Pujol, D., Guillaume, E. M., Todd, E., Nave, C. S., Sherman, R. A., Ziegler, M., Jones, A. B., \& Funder, D. C. (2014). The Situational Eight DIAMONDS: A taxonomy of major dimensions of situation characteristics. Journal of Personality and Social Psychology, 107(4), 677-718.

Ro, E., \& Clark, L. A. (2009). Psychosocial functioning in the context of diagnosis: Assessment and theoretical issues. Psychological Assessment, 21(3), 313-324.

Ro, E., \& Clark, L. A. (2013). Interrelations between psychosocial functioning and adaptive- and maladaptive-range personality traits. Journal of Abnormal Psychology, 122(3), 822-835.

Robins, E., \& Guze, S. B. (1970). Establishment of diagnostic validity in psychiatric illness: its application to schizophrenia. American journal of psychiatry, 126(7), 983-987.

Rogers, C.R. (1951). Client-centered therapy. Houghton Mifflin.

Ruggero, C. J., Kotov, R., Hopwood, C. J., First, M., Clark, L. A., Skodol, A. E., ... \& Zimmermann, J. (2019). Integrating the Hierarchical Taxonomy of Psychopathology (HiTOP) into clinical practice. Journal of consulting and clinical psychology, 87(12), 1069-1084.

Samuel, D. B., Sanislow, C. A., Hopwood, C. J., Shea, M. T., Skodol, A. E., Morey, L. C., ... \& Grilo, C. M. (2013). Convergent and incremental predictive validity of clinician, selfreport, and structured interview diagnoses for personality disorders over 5 years. Journal of consulting and clinical psychology, 81(4), 650. 
Samuel, D. B., Simms, L. J., Clark, L. A., Livesley, W. J., \& Widiger, T. A. (2010). An item response theory integration of normal and abnormal personality scales. Personality Disorders: Theory, Research, and Treatment, 1(1), 5.

Samuel, D. B., \& Widiger, T. A. (2008). A meta-analytic review of the relationships between the five-factor model and DSM-IV-TR personality disorders: A facet level analysis. Clinical psychology review, 28(8), 1326-1342.

**Sauer-Zavala, S., Southward, M. W., \& Semcho, S. A. (in press). Integrating and differentiating personality and psychopathology in cognitive behavioral therapy. Journal of Personality.

Saulsman, L. M., \& Page, A. C. (2004). The five-factor model and personality disorder empirical literature: A meta-analytic review. Clinical psychology review, 23(8), 1055-1085.

Simms, L. J., Goldberg, L. R., Roberts, J. E., Watson, D., Welte, J., \& Rotterman, J. H. (2011). Computerized adaptive assessment of personality disorder: Introducing the CAT-PD project. Journal of Personality Assessment, 93(4), 380-389.

Simms, L.J., Wright, A.G.C., Cicero, D., Kotov, R., Mullins-Sweatt, S.N., Sellbom, M., Watson, D., Widiger, T.A., \& Zimmermann, J. (in press). Development of measures for the Hierarchical Taxonomy of Psychopathology (HiTOP): A collaborative scale development project. Assessment.

Sperry, S., Sharpe, B.M., \& Wright, A.G.C. (2021). Momentary dynamics of emotion-based impulsivity: Exploring associations with dispositional measures of internalizing and externalizing psychopathology. Manuscript submitted for publication.

\section{https://psyarxiv.com/352e9/}

Stein DJ, Palk AC, Kendler KS (2021). What is a mental disorder? An exemplar-focused 
approach. Psychological Medicine 51, 894-901. https://doi.org/10.1017/ S0033291721001185

Sullivan, H.S. (1953). The interpersonal theory of psychiatry. Norton.

Suzuki, T., Samuel, D. B., Pahlen, S., \& Krueger, R. F. (2015). DSM-5 alternative personality disorder model traits as maladaptive extreme variants of the five-factor model: An itemresponse theory analysis. Journal of abnormal psychology, 124(2), 343.

Thielmann, I., Zimmermann, J., Leising, D., Hilbig, B. E., \& Back, M. (2017). Seeing is knowing: On the predictive accuracy of self-and informant reports for prosocial and moral behaviours. European Journal of Personality, 31(4), 404-418.

Thomas, K. M., Yalch, M. M., Krueger, R. F., Wright, A. G., Markon, K. E., \& Hopwood, C. J. (2013). The convergent structure of DSM-5 personality trait facets and five-factor model trait domains. Assessment, 20(3), 308-311.

Waugh, M.H., Hopwood, C.J., Krueger, R.F., Morey, L.C., Pincus, A.L., \& Wright, A.G.C. (2017). Psychological assessment with the DSM-5 Alternative Model for personality disorders: Tradition and innovation. Professional Psychology: Research and Practice, 48(2), 79-89.

Widiger, T.A., Sellbom, M., Chmielewski, M., Clark, L.A., DeYoung, C.G., Kotov, R., Krueger, R.F., Lynam, D. R., Miller, J.D., Mullins-Sweatt, S., Samuel, D.B., South, S.C., Tackett, J.L., Thomas, K.M., Watson, D., \& Wright, A.G.C. (2019). Personality in a hierarchical model of psychopathology. Clinical Psychological Science, 7(1), 77-92.

Wiggins, J. S. (Ed.). (1996). The five-factor model of personality: Theoretical perspectives. Guilford Press.

Williams, J. B. W. (1985). The multiaxial system of DSM-III: Where did it come from and 
where should it go? Archives of General Psychiatry, 42, 175- 180.

**Wilson, S., \& Olino, T.M. (in press). A developmental perspective on personality and psychopathology across the life span. Journal of personality.

Woods, W.C., Arizmendi, C., Gates, K.M., Stepp, S.D., Pilkonis, P.A., \& Wright, A.G.C. (2020). Personalized models of psychopathology as contextualized dynamic processes: An example from individuals with borderline personality disorder. Journal of Consulting and Clinical Psychology, 88(3), 240-254. https://psyarxiv.com/amdu8/

World Health Organization. (2019). International statistical classification of diseases and related health problems (11th ed.).

Wright, A.G.C. (2017). Factor analytic support for the five-factor model. In T.A. Widiger (Ed.) Oxford handbook of the five-factor model (pp. 217-242). Oxford, UK: Oxford University Press.

Wright, A.G.C., Gates, K.M., Arizmendi, C., Lane, S.T., Woods, W.C., \& Edershile, E.A. (2019). Focusing personality assessment on the person: Modeling general, shared, and person specific processes in personality and psychopathology. Psychological Assessment, 32(4), 502-515. https://osf.io/nf5me/

Wright, A.G.C., Hopwood, C.J., Skodol, A.E., \& Morey, L.C. (2016). Longitudinal validation of general and specific structural features of personality pathology. Journal of Abnormal Psychology, 125(8), 1120-1134.

Wright, A.G.C., Hopwood, C.J., \& Zanarini, M.C. (2015). Associations between changes in normal personality traits and borderline personality disorder symptoms over 16 years. Personality Disorders: Theory, Research, and Treatment, 6(1), 1-11.

Wright, A.G.C., \& Kaurin, A. (2020). Integrating structure and function in conceptualizing and 
assessing pathological traits. Psychopathology, 53, 189-197. https:// osf.io/6fe9d

Wright, A.G.C., Pincus, A., \& Hopwood, C.J. (2021). Contemporary integrative interpersonal theory: Integrating structure, dynamics, temporal scale, and levels of analysis. Manuscript submitted for publication. https://doi.org/10.31234/osf.io/fknc8

Wright, A.G.C., \& Simms, L.J. (2014). On the structure of personality disorder traits: Conjoint analyses of the CAT-PD, PID-5, and NEO-PI-3 trait models. Personality Disorders: Theory, Research, and Treatment, 5(1), 43-54.

Wright, A.G.C. \& Simms, L.J. (2015). A metastructural model of mental disorders and pathological personality traits. Psychological Medicine, 45(11), 2309-2319.

Wright, A.G.C. \& Woods, W.C. (2020). Personalized models of psychopathology. Annual Review of Clinical Psychology, 16, 49-74. https://psyarxiv.com/6hqzj/

Wright, A.G.C. \& Zimmermann, J. (2019). Applied ambulatory assessment: Integrating idiographic and nomothetic principles of measurement. Psychological Assessment, 31(12), 1467-1480. https://psyarxiv.com/6qc5x/

Wrzus, C., \& Roberts, B. W. (2017). Processes of personality development in adulthood: The TESSERA framework. Personality and Social Psychology Review, 21(3), 253-277.

Zachar, P. (2014). A metaphysics of psychopathology. MIT Press.

Zachar, P., Krueger, R. F., \& Kendler, K. S. (2016). Personality disorder in DSM-5: An oral history. Psychological Medicine, 46(1), 1. 
Table 1. Person variable and problem variables.

\begin{tabular}{|c|c|}
\hline Personality & Psychopathology \\
\hline $\begin{array}{l}\text { Adaptive } \\
\text { Normal } \\
\text { Normative } \\
\text { Individual Difference } \\
\text { Personality Style } \\
\text { Personality Trait } \\
\text { Personality Type }\end{array}$ & $\begin{array}{l}\text { Abnormal } \\
\text { Atypical } \\
\text { Disease } \\
\text { Disorder } \\
\text { Dysfunction } \\
\text { Maladaptive } \\
\text { Mental Health } \\
\text { Psychopathology } \\
\text { Problem } \\
\text { Sign } \\
\text { Symptom } \\
\text { Syndrome }\end{array}$ \\
\hline \multicolumn{2}{|c|}{ Personality and Psychopathology } \\
\hline \multicolumn{2}{|c|}{$\begin{array}{c}\text { Personality Disorder } \\
\text { Maladaptive Trait } \\
\text { Psychopathology Dimension } \\
\text { Transdiagnostic Dimension }\end{array}$} \\
\hline
\end{tabular}


Table 2. Five recommendations for future work on personality and psychopathology, example implementations, and challenges

\section{Recommendation}

1 Identify contributions of person, context, and their interaction

2 Map the temporal course of behavior over multiple time scales

3 Distinguish behavior and dysfunction in assessments

4 Match methods of data collection to level of functioning

5 Study individuals who exhibit specific contextualized processes

\section{Implementation}

Assess both individual behavior and information

about contexts

Assess behavior repeatedly over time to map

temporal course, ideally at multiple time scales

Use or develop measures that cleanly separate behavior and dysfunction

Use multimethod assessments

Use idiographic/personalized models to identify individuals with specific processes
Challenge

Difficult to comprehensively sample relevant behaviors and context

Current theory often lacks temporal specificity

Difficult to write items that are valence neutral

Method variance often large relative to psychological trait variance; Requires

interpreting in context of processes involved

Resource and computation intensive 